\title{
Second Language Learners' Strong Preference for Self-initiated Self-repair: Implications for Theory and Pedagogy
}

\author{
Simin Zeng \\ School of Humanities and Social Sciences, Harbin Institute of Technology, Shenzhen, China
}

\begin{abstract}
This study employs a theoretical framework informed by Conversation Analysis to analyse the self-repairs of a particular group of teenage Chinese EFL learners. With an aim to report on the current development of the participants in using English socially in terms of managing repairs, this study explores their second language (L2) discourse in three communicative tasks. Audio-recorded conversations were analysed and searched for the four sequences of repair. Comparison of the participants' preference for repair sequence to native speakers shows that they can manage repairs and maintain conversation interactively and socially just as native speakers. This suggests that they should be treated as normal social beings in the language classroom and not to be interrupted by the teacher when troubles arise from conversational interaction. Thus, this study provides an account of the current development of these young learners in using the L2 interactively and socially, which holds implications for research on second language education as well as for classroom teaching.
\end{abstract}

Index Terms - self-repair, conversation, analysis, second language education

\section{INTRODUCTION}

Repair is understood as alterations made to prior speech to deal with certain problems. Self-repair, in particular, refers to the kind of repair in which a speaker changes a part of his/her speech to manage a problem of his/hers. The problems can be related to a speaker's own production, the interlocutor's comprehension and their two-way interaction.

This study focuses on the self-repair behaviour of a group of teenage Chinese EFL learners. Their self-repairs are investigated to understand the current development of these young learners in using the L2 interactively and socially. The repair behaviour based in these teenage EFL learners' classroom discourse is considered worthwhile for study for two reasons. First, concerning the subjects - teenage learners, they constitute the majority of English learners in China. Second, as for the context of study - the classroom, it is where the most common and regular form of English language learning and teaching in China takes place. By placing the lens of study in the classroom discourse of these young learners in their English lessons, an as broad and meaningful perspective as possible can be gained to study L2 self-repairs.

The theoretical framework that has influenced and informed this study is Conversation Analysis, from which the study of self-repair originated. Conversational analytic perspective sees speakers as interactants and self-repairs as an organisational mechanism in conversational interaction. It seeks to understand the operation of repair in social language use. In the bulk of CA-oriented work, the most important and relevant result to this study is reported by a group of ethnographers, Schegloff, Jefferson and Sacks (1977), that self-initiated self-repair is the most preferred repair sequence of native speakers. They attributed this strong preference for self-repair to the ordering of turns in conversation. Initially, their results were not intended to shed light on L2 education.

This study follows conversational analytic traditions and aims to generate knowledge that can inform research and pedagogy in L2 education. To be more specific, this study attempts to identify the different repair sequences in L2 speakers' discourse, which is collected from their performance in communicative tasks, and to discover whether learners show the same preferences for repair sequence as native speakers. A comparison between the participating learners and native speakers is expected to shed light on the following issues: whether the self-repair behaviour of L2 learners are constrained by the same factors as native speakers; whether L2 learners have developed the ability to manage repairs, to maintain a conversation and to use the language interactively and socially as native speakers. These answers can contribute to an understanding of the current status of socialisation of learners into the L2 community and generate implications for related research.

Results of the study will be linked back to the language classroom. It will suggest suitable treatments for the teachers to apply to L2 learners' problems that arise from their interaction during tasks. Questions such as whether the teacher should stop a speaker when his/her production contains trouble, and whether the teacher's treatment towards learner problem should differ according to task types will be answered. 


\section{LITERATURE REVIEW}

This section will begin by introducing the most important CA theories related to self-repair, followed by an overview of empirical studies based in the L2 classroom that bear the most relevance to the current study. Gaps that inform the research questions of this particular study will be identified at the end.

\section{A. The Conceptualisation of Repair in CA}

The concept of "repair" originated from conversational analytical studies (Jefferson, 1974; Schegloff, Jefferson \& Sacks, 1977), where it is conceptualised as an organisational mechanism operating in conversational turn-taking behaviour. Repair is described as a conversational device that addresses "recurrent problems in speaking, hearing, and understanding" (Schegloff et al., 1977, p. 361). The problem that is encountered in the production of an utterance and that triggers attempts to solve it is referred to as a "trouble source", be it a problem of factual knowledge or of language use by the interlocutors.

Within the framework of CA, researchers prefer to adopt the term "repair" instead of "correction". Though "repair" and "correction" are both corrective activities, they are not two equivalent terms. "Correction" refers to the replacement of an error with a correct utterance. "Repair", on the other hand, is found sometimes occurring in cases where no noticeable error is detected. Thus, Schegloff, Jefferson and Sacks (1977) have suggested that "repair" should be used to account for the much wider phenomenon.

Studying repair is considered necessary and worthwhile not only because it is a frequently occurring phenomenon in the most common use of language - conversation, but also because the organisation of repair is the self-righting mechanism for dealing with intrinsic troubles in language use.

\section{B. Four Trajectories of Repair}

Researchers following the CA approach study repair in the domain of conversational interaction and distinguish between four different types of repair sequences in terms of the two possible agents (i.e., "self" and "other") who can initiate and/or complete a repair. With reference to "self" and "other", a distinction is drawn between self-repair and other-repair, the former referring to a repair by the producer of the trouble source while the latter is a repair by the listener. A self-repair can result from self-initiation (SISR) or other-initiation (OISR). An other-repair can be initiated by the producer of the trouble source (SIOR) or the interlocutor (OIOR). In the later discussion in this paper, the notion of "self-repair" includes both types of SISR and OISR. Below, examples (from Schegloff et al., 1977) of each kind are illustrated. Lines marked with arrows indicate that they contain the initiations and completions of repairs, which are in italics.

Self-initiated self-repair (SISR): the producer of the trouble source initiates and completes the repair.

(1)

$\mathrm{N}$ : $\quad$ She was giving me a:ll the people that

$\rightarrow \quad$ were go:ne this yea:r I mean this

$\rightarrow \quad$ quarter $\mathrm{y}^{\prime} / /$ know

J: $\quad$ Yeah

Other-initiated self-repair (OISR): the interlocutor, other than the speaker of the trouble source, identifies a problem and initiates a repair, which is then completed by the producer of the trouble source.

(2)
Ken: Is Al here today?
Dan: Yeah.
$\rightarrow \quad$ Bob: He is? hh eh heh
$\rightarrow \quad$ Dan: Well he was.

Self-initiated other-repair (SIOR): the producer of the trouble source initiates a repair, but it is later completed by the interlocutor.

B: He had dis uh Mistuh W- whatever k-

$\rightarrow \quad$ I can't think of his first name, Watts on, the one that wrote $1 /$ that piece,

$\rightarrow \quad$ A: Dan Watts.

Other-initiated other-repair (OIOR): the interlocutor initiates and completes the repair.

(4) Lori: But y'know single beds'r awfully thin tuh sleep on.

$\rightarrow$ Sam: What?

Lori: $\quad$ Single beds. // They're-

$\rightarrow \quad$ Sam: Y'mean narrow?

Lori: They're awfully narrow // yeah.

\section{Preference for Self-initiated Self-completed Repair}

Empirical research has shown that in L1 everyday talk, speakers have a strong and robust preference for self-initiated self-repair. This was initially reported and described by Schegloff et al. (1977) following their close examination of a huge corpus of conversations between native adult speakers in daily life settings. It is revealed that self-repair is vastly more common than other-repair as participants jointly construct meanings in and through sequential order of action and talk (Wagner \& Gardner, 2004). As further stressed by Schegloff et al. (1977), self-repair and other-repair are not two independent types of possibilities. Instead, they are related and constrained by the organisational mechanism operating 
in conversation, especially the turn-taking system. Evidence for the preference for self-repair lies in the inherent structural bias in conversational interaction (Seedhouse, 2004): with the first two opportunities to repair a speaker's own trouble in his/her own turn. As Hutchby and Wooffitt (1998, p. 66) put it, "turns are designed to facilitate self-repair, or display the speaker's sensitivity to the appropriateness of self-repair and the (possible) impropriety of other-repair."

\section{Language Socialisation}

Countering to the unveiling and the description of a predominant preference for self-initiated self-repair in conversation of adult native speakers, an exceptional context in which other-initiations and other-repairs prevail is adult-children talk (Schegloff et al., 1977). This is accounted for by the children's not-yet-competent nature of operating in the social domain of talk and conversation. The occurrences of other-initiations and other-repairs in this case are termed as "a vehicle for socialisation" $(1977$, p. 380) by the writers. It is assumed that after this transitional phase dominated by other-adjustments, with adequate competence acquired, the formerly not-yet-competent users of self-initiations and self-repairs will demonstrate the routine organisation of repair in conversation in their talk. When learning an L2, learners are put in a similar position to children - they are considered as veterans or novice of the majority community. They learn to understand and use the target language through social experiences of participating in community activities, in this case, in the language classroom (Sarangi \& Roberts, 2002; Ochs, 2002). How learners' preference for different sequences of repair can be mined for insights into their language socialization is under-researched.

\section{E. The Organisation of Repair in Language Classroom}

Schegloff et al.'s (1977) finding that in natural conversation, interactants' preference is given to self-initiation and self-repair has been examined and applied in research on L2 education. Studying the organisation of repair in the language classroom is of value for L2 teachers and learners for it helps to understand how misunderstandings and breakdowns in communication are managed (Seedhouse, 1999, 2004).

Both naturalistic classroom research (Buckwalter, 2001) and classroom experiment (Shehadeh, 2001) have been conducted to investigate the repair phenomena in learner discourse. Results from their analysis show a clear preference for self-initiation and self-repair as learners participate in communicative tasks. They prove that the preferences of non-native speakers in repair sequences are in line with that of adult native speakers of English. As for pedagogical practices, Buckwalter (2001) supports the use of communicative activities in the language classroom as this can encourage learners' language production and provide them with more opportunities to identify trouble in their speech and reformulate their utterances. However, it is not specified what treatments towards learners' problems and their repair attempts to solve these problems are recommended. Shehadeh (2001) concludes that both self-initiation and other-initiation matter for learning and suggests that other-initiated adjustments can positively affect learners' repair behaviour during communicative activities by reminding them of a correct solution.

A "variable" approach (Van Lier, 1988; Kasper, 1985; Jung, 1999) has been proposed to understand repair in the L2 classroom, which argues that the organisation of repair differs in contexts with different pedagogical goals. Van Lier (1988) analysed how repairs were conducted to orient to different goals in L2 classrooms and suggested that repair was highly relevant to the activity and context where it occurred. Kasper (1985) identified two different phases in L2 lessons: language-centred and content-centred. According to her, learners' preference for repair patterns depends heavily on the type of classroom activity. In language-centered activities, the most prevalent repair sequence is other-initiated self-repair, in which case the teacher initiates and the learner completes the repair. Content-based activities, with a focus on the meaningful use of the target language, on the other hand, see less occurrences of this repair sequence. Seedhouse $(1999,2004)$ extended the 'variable' approach to repair in the L2 classroom and suggested a context-based element to enrich it. According to Seedhouse (2004), L2 classroom context is by no means a "monolithic or undifferentiated whole" (p. 142). He identified three types of context: (1) form-and-accuracy context; (2) meaning-and-fluency context; and (3) task-based context, and studied the repair patterns in these contexts. He concluded that each context had its particular pedagogical focus and its typical repair organisation, and there was a reflexive relationship between them.

These studies discussed above contribute to our knowledge of the repair phenomena in learner discourse in L2 classroom. However, they are primarily descriptive and are limited in terms of pedagogical implications. Plus, none of them reflects on the socialisation process of L2 learners in the classroom context in terms of their repair behaviour.

\section{F. Repair Behaviour of Chinese EFL Learners}

More recently, L2 self-repair behaviour of Chinese learners has also been investigated. Chen and Pu (2007) analysed the features of self-repairs of college non-English majors in the CET (College English Test), while factors such as age differences (Wang, 2007) and gender differences (Chen, Li \& Zhao, 2005) in self-repairs of Chinese college students studying English have also been the focus of attention. However, these studies did not shed light on the interactive or social aspects of learners' execution of self-repairs and none of them examined teenage Chinese learners' self-repairs.

\section{G. Identification of Gaps}

The above review on repair shows that a CA approach to studying L2 learners' self-repairs is of value but has not focused on generating specific suggestions for research and pedagogy concerning L2 learners yet. Researches on the 
repair behaviour of L1 speakers have provided a clue for the socialisation of native-speaking children. Notwithstandingly, the socialisation of L2 learners into a community of a different language, especially in the perspective of producing the different repair sequences, has not been touched upon.

\section{Methods}

Informed by the gaps identified in the Literature review, two research questions were generated as follow:

RQ1: What is the most common repair sequence of teenage Chinese EFL learners?

RQ2: What implications do this hold for research and pedagogy?

\section{A. Research Methodology}

This study adopted the case study approach. With a focus on learners' L2 behaviour which primarily occurs within the language classroom, and considering the limited time for the researcher to engage with the young participants and collect data from them, as allowed by the school authority through negotiation, the researcher engaged in a short-term, small-scale classroom-based case study.

\section{B. Participants}

The participants were six teenage Chinese EFL learners in their $3^{\text {rd }}$ year at Secondary school (15-year-old). Equally divided between the two genders, the participants were organised into three pairs: boy-girl, boy-boy and girl-girl. These selected students were all at lower intermediate level of proficiency. This was different from previous studies of L2 self-repairs (van Hest, 1996; Kormos, 1998), in which participating learners were at different levels of proficiency, ranging from beginners to advanced learners. The reason behind this had to do with the context of the study - the language classroom, in which the teacher would engage with learners who were more or less similar in terms of their proficiency level (Kazemi, 2006). They had learned English for more than six years. The majority of them had no prior living or learning experience in English-speaking countries. It might be questioned that there was too small a number of participants to generate insights. Here, a defense would be drawn with reference to the nature and focus of this study: a close examination of repair in learner discourse. Including a large number of participants could sacrifice the depth of analysis into the details of talk, which is against the focus of this study.

\section{The Tasks}

In this study, data were collected by means of three pair-work communicative tasks. The format of the tasks was decided to be pair work between students because (1) it would fulfill the aim of this study which focuses on self-repairs during learner-learner interaction; (2) both the participants and their English teacher stated that pair-work discussion was part of their regular classroom activities and that participants were familiar with it.

The participants were offered four tasks in which they chose three. The four tasks included were initially chosen by the researcher because (1) they were recognised by researchers (e.g., Pica, Kanagy \& Falodun, 2009) as the task types that could generate most opportunities for L2 production and interlanguage modification in the classroom; (2) they had proved to be the most effective ones in eliciting spontaneous speech and learner-learner interaction in the pilot study. The three tasks decided by the participants were (1) the information-gap task "ask the right question, (2) the story telling task and (3) the jigsaw task "complete the picture". The task topics and contents had been discussed with and approved by their English teacher.

\section{Data Collection}

Learners' self-repair data was collected through audio recording. A complete record of the utterances made by the three pairs of participants during their engagement in each of the three tasks was captured and made available through time for analysis. This was made possible by placing a tape recorder on the desk between the two participants when they were talking. The sound quality it resulted in was excellent.

\section{E. Data Analysis}

To enable thorough analysis of data for quantification of the four repair sequences, the full text generated from the participants' task performance was transcribed (see transcription notation in Appendix A). The four different types of repair sequences suggested by earlier conversational analysts were identified and distinguished in the corpora. Reporting of them was accompanied by illustrating examples of each type of repair sequence found in participants' conversational data. Counting, a form of quantification, was applied to obtain the number of cases of each repair sequence, and to generate respective ratios that then enabled comparison. By comparing the number of the different repair sequences in participants' conversational data, their preferences were indicated. Most importantly, these L2 learners' preferences in repair would be examined to see if they were in line with what native speakers had shown.

\section{RESUlts}

By analysing the full transcripts of the nine independent conversations made by the three pairs of participants, a sum of 198 instances of repairs were identified. They were analysed with reference to the two possible agents - "self" and 
"other", who can either initiate or complete the repair.

Next, examples of identified SISR, OISR and SIOR will be discussed. No cases of OIOR were identified in the data.

(5) $\rightarrow$ Ann: on the (.) on the east of the carpet there (.) oh no!

Ken: What happened?

$\rightarrow \quad$ Ann: $\quad$ er on the east of the sofa there is a:: coffee table.

Lori: They're awfully narrow // yeah.

This is an example of SISR. Ann was describing the position of the coffee table to Ken when she said "on the east of the carpet". Then shortly, and suddenly, she called out "oh no" when she realised a mistake in her speech. This is the initiation of repair. Ken immediately responded to Ann by asking what her concern was. Following this, Ann replaced "carpet" with "sofa", thus, repairing the trouble.

$$
\begin{array}{lll} 
& \text { May: } & \text { it's a:: singer (.) she is (.) dead } \\
\rightarrow & \text { Sue: } & \text { many singer is dead (.) were dead. }
\end{array}
$$

This is also an example of SISR. May was giving Sue clues to guess the name of a singer. In Sue' s response, she initiated and completed a repair in the same turn by replacing the verb "is" with "were" to go with the adjective, many, which assumes plurality, and the fact that it is in the past that they died.

$$
\begin{aligned}
& \text { Sue: yah on the same line same line. So do you have:: (.) garden chairs? } \\
& \text { May: yes the garden chair is::(.) er is in the balcony (.) right one and (.) left one } \\
& \rightarrow \text { Sue: one? one?// } \\
& \rightarrow \quad \text { May: one in right and (.) one in (.)/// left }
\end{aligned}
$$

This is an example of OISR. May was attempting to describe the different positions of the two garden chairs on the balcony when she said "right one and left one". However, her description was confusing to Sue. So Sue partially repeated the trouble source in a rising tone and this initiated May's repair in the next turn, in which she changed "right one and left one" to "one in right and one in left".

(8) Ann: when someone is in (.) dangerous wha what do he:: say

$$
\begin{array}{lll}
\rightarrow & \text { Ken: } & \text { 什么?(what?) } \\
\rightarrow & \text { Ann: } & \text { In danger. }
\end{array}
$$

This is also an example of OISR. In the beginning, Ann wrongly collocated the two words "in" and "dangerous" together which confused Ken. So Ken asked "什么? ", which meant "what?" in English and this reminded Ann of her mistake in the previous turn and initiated her repair in the next turn, by changing "in dangerous" to "in danger".

$$
\begin{array}{ll}
\text { Tim: the manager (.) take took him in (.) took him with took him to the } \\
\text { (.) security guard's room and the security guard ask the woman where's } \\
\text { the (.) where's the (.) em:: wine from, and the woman was (.) so::= } \\
\rightarrow \quad \text { Roy: nervous= } \\
\text { Tim: yeh, so nervous but (.) but he }
\end{array}
$$

This is an example of SIOR. In the beginning, Tim introduced part of a story and was about to describe the woman's feeling when he encountered difficulties in searching for a proper word. The stretching of the sound /o/ in "so" was considered his indication of a problem in speech and the initiation of a repair. This was followed by Roy saying "nervous", completing the repair. With the problem in word search solved, Tim continued with his story in the next turn.

Having presented how a repair is identified as belonging to which certain type of repair sequence, two graphs that were generated from the quantification of all repairs are shown below.

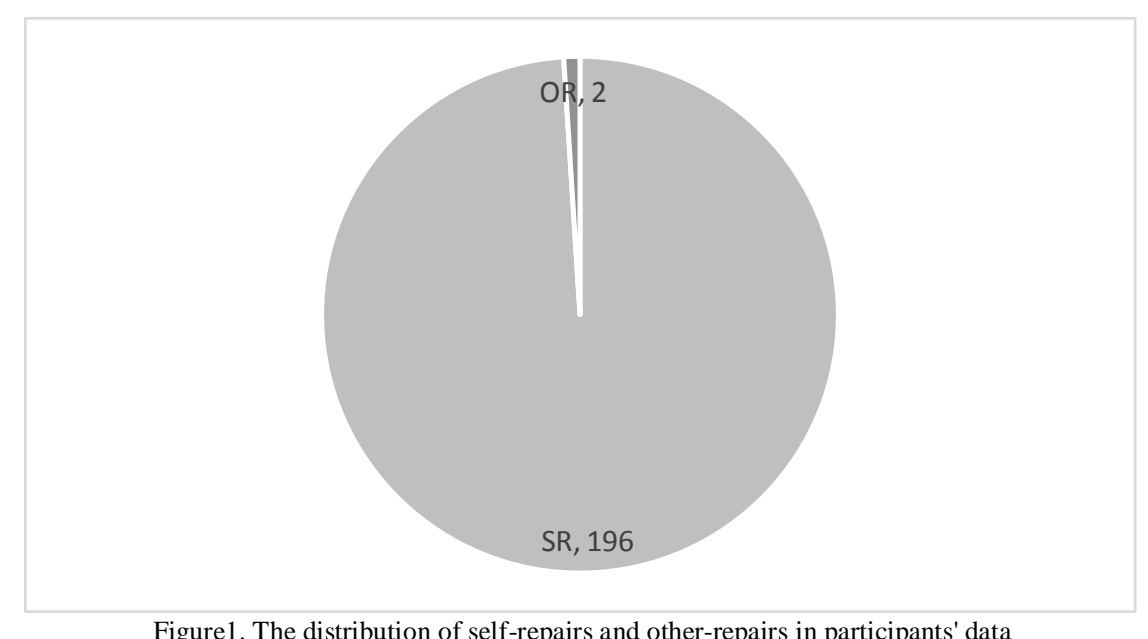

Figure1. The distribution of self-repairs and other-repairs in participants' data 


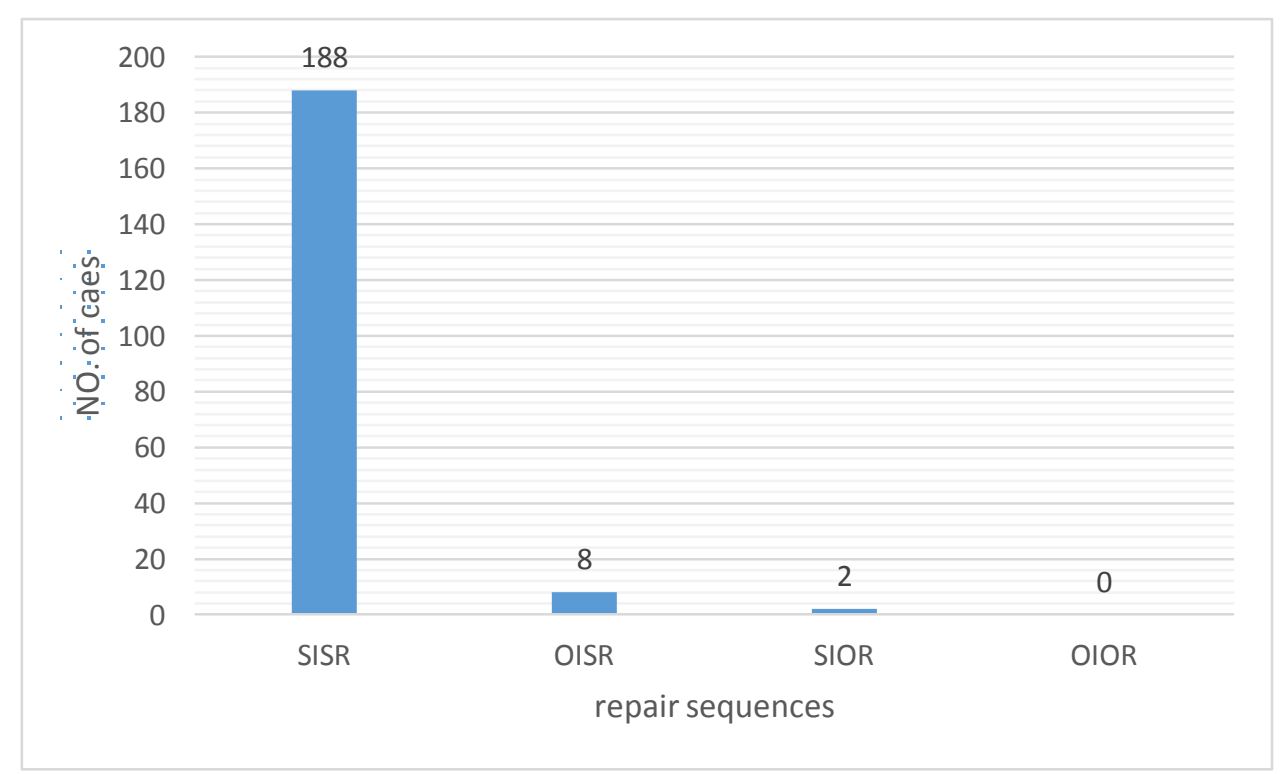

Figure 2: The distribution of the 4 types of repair sequences

The pie chart in Fig. 1 and the bar graph in Fig. 2 have enabled comparisons of the number of occurrences of different repair sequences in a more straightforward manner. Fig. 1 demonstrates that participants showed a overwhelmingly strong preference for self-repairs to other-repairs, as $99 \%$ of the instances are self-repairs. Fig. 2, which further breaks the two general categories, self-repairs and other-repairs, down into four independent types of repair sequences, SISR, OISR, SIOR, and OIOR, shows that the vast majority of repairs produced are self-initiated self-repairs, with $95 \%$ of the 198 cases belonging to the category of SISR. OISR constitutes for $4 \%$ of all instances, ranking the second most commonly occurring repair sequence. The remaining $1 \%$ are two cases of SIOR and no instance of OIOR is identified from the collected data.

\section{DISCUSSION}

The current study focuses on teenage Chinese EFL learners' conversational repairs during classroom communicative tasks. Analysis of results has clearly revealed that this particular group of teenage non-native speakers of English show a predominant preference for self-initiated self-repairs.

The participants demonstrated exactly the same characteristics as adult native speakers of English in the management of repairs during conversational interaction. Notwithstanding their limited proficiency in the target language, they managed conversational interaction in the same manner, in terms of the organisation of repair, as adult native speakers do. Specifically, in most of the cases identified in the data, they realised a trouble without being reminded, initiated a repair by themselves and completed it with their own efforts. Seldom did they intend to remind the interactants of his/her troublesome production or correct a problematic item produced by their interactants. The fact that they were not native speakers of the language did not endanger their ability to maintain conversational interaction with an interlocutor. Although they were in the process of learning a language, it did not interfere with their ability to use the language interactively and socially.

This shows that, as far as the ability to converse is concerned, "non-native speakers" are normal social beings just like native speakers, which holds implications for both research and pedagogy.

For research, it must be pointed out that the abstraction of "non-native speaker versus native speaker" is distorted. The fundamental difference between these two groups is only in terms of their linguistic competence. However, "non-native speakers" have been alienated as a social group that is fundamentally different from native speakers. Such distinction between "non-native speaker" and native speaker is commonly observed in past research topics, for example, Variation in Native Speaker Speech Modification to Non-Native Speakers (Gass \& Varonis, 1985), Delayed next turn repair initiation in native/non-native speaker English conversation (Wong, 2000). As is shown in the current study, there is not any qualitative difference between "non-native speaker" and "native speaker" in terms of managing troubles when using the language interactively and socially. The label of "non-native speaker" placed on L2 learners does not prevent them from successfully cooperating in communication and maintaining social interaction. Thus, it is argued that L2 learners are functioning just the same as native speakers in using a language interactively and socially, so they should not be treated as a distinct social group in research.

The results also hold implications for pedagogy. In classroom teaching, teachers should realise that their students are in the process of being socialised into another community in which the target language is used. That is to say, the students should be prepared to use the language socially, to communicate with the language and to construct a conversation in the language.The researcher agrees with Buckwalter's (2001) advice that L2 learners should be engaged 
in more communicative activities in which they can have more opportunities during the process to detect problems and figure out solutions. However, one step needs to be taken further from here. In communicative activities, whenever a problem is identified by the interactants in their conversation, the teacher's reaction - what he/she does towards learner problems, is important and should follow some guidelines. The suggestion proposed by the researcher is opposite to what Shehadeh (2001) has advised. According to Shehadeh (2001), other-initiated adjustments, including teacher-initiated repairs, can promote second language learning as it reminds the speaker of an error-free solution, thus, increasing his/her language accuracy. On the contrary, the researcher believes that the teacher should not initiate a repair upon hearing learner's problematic production during communicative task performance. The reason lies in the nature and purpose of communicative activities, which is to train learners' communicative skills, to enable them to have the ability to converse and maintain interaction in the target language and to provide them with opportunities of using the L2 communicatively and socially.

In conducting communicative activities, teachers are not advised to interrupt a learner during his/her flow of spontaneous speech even if errors occur. As has been reported by Schegloff et al. (1977), the only circumstance in which other-initiated adjustments prevail is conversations between fully-competent language users and not-yet competent language users in the social domain, like parent-children talk. Though L2 learners do not have full linguistic competence, they have proved to be normal social beings, as is shown in their management of repairs. As a result, they should be treated correspondingly in the language classroom and be given the chance and right to self-initiate a repair. Otherwise, the language classroom turns into a protective environment, in which learners would possibly develop some habits that are socially inappropriate in the community in which the target language is used. In speaking, they would tend to spend more time planning speech because they focus more on language accuracy and avoiding linguistic errors. This can lead to inefficient communication that is unfavourable in social interaction. In hearing and interacting, because of their sensitivity to inaccuracy, they would possibly point out problems in their interlocutors' speech and initiate repairs. This is against social norms in the L2 community in which native speakers' language use presented a strong skewing towards self-initiations and self-repairs. Therefore, in learners' use of the L2 during communicative activities, their preference for the self-initiated self-repair sequence should not be interrupted by their teacher.

There may be concern that without the intervention of teacher-initiated adjustments, the accuracy of learners' production will be endangered. In fact, this can be taken care of in other kinds of activities which focus on linguistic accuracy, rather than communicative activities which particularly aim to help L2 grow in communicative competence.

\section{CONCLUSION}

Adult speakers' strong bias for self-initiated self-repairs has been known for decades. It is in more recent research related to second language education that adult non-native speakers' preference for self-initiated self-repairs is revealed and studied (e.g., Kasper, 1985; Shehadeh, 2001; Buckwalter, 2001). However, the socialisation process of language learners into the L2 community in terms of their repair management, which can have some significance for both research and pedagogy, was under-researched. Therefore, the present study fills the gap by examining L2 learners' self-repairs and seeks to understand the current development of these learners' capabilities in using the L2 interactively and socially, and generate possible implications for research and pedagogy.

The examination of the L2 learners' repair in this study shows that, when participating in communicative tasks as interactants, they proved to be successfully functioning social beings in the same way as native speakers in terms of the management of repairs. This can have certain significance for research in second language education, as it informs that in spite of the difference in terms of linguistic competence, a line should no longer be drawn between non-native speakers and native speakers, as both these two groups have the same characteristics - a strong preference for self-initiated self-repair in the organisation of conversation. This can also hold implications for pedagogy. It is suggested that in classroom teaching, what the teacher does in reaction to learners' problems and their self-repairs should differ according to pedagogical aims. In communicative activities that focus on training learners' ability to converse and interact in the target language, whenever a learner's trouble arises from his/her conversation with an interlocutor, the teacher should not interrupt his/her speech to initiate a repair because such attempts are not in line with common practices in an interactive and social context and can negatively affect the learners' development of using a language interactively and socially. In other cases, for example, activities that are designed to improve learners' accurate use of language, teacher-initiated adjustments can be recommended.

\section{APPENDIX. TRANSCRIPTION NOTATION}

they Underlined fragments indicate speaker emphasis.

(.) A short pause

(+) A long pause

$=\quad$ Contiguous utterances: when there is no interval between adjacent utterances, the second being latched immediately to the first (without overlapping it), the utterances are linked together with equal signs

(( ) ) A description enclosed in a double bracket indicates a non-verbal activity. Alternatively double brackets may enclose the transcriber's comments on contextual or other features. 
? A question mark indicates a rising intonation. It does not necessarily indicate a question.

- A full stop indicates a stopping fall in tone. It does not necessarily indicate the end of a sentence.

:: $\quad$ Colons indicate that the speaker has stretched the preceding sound or letter. The more colons the greater the extent of the stretching.

underline Unerlined words mark a section of speech noticeably louder than that surrounding it.

italics trouble source and repair

( ) Empty parentheses presents translations of preceding words.

\section{ACKNOWLEDGEMENTS}

This work was supported in part by a grant from University of Cambridge Wolfson College. The author wishes to thank Dr Edith Esch, Dr Michael Evans and Dr Yongcan Liu for their feedbacks and comments on earlier drafts of this paper.

\section{REFERENCES}

[1] Buckwalter, P. (2001). Repair sequences in Spanish L2 dyadic discourse: A descriptive study. The Modern Language Journal, 85(3), 380-397.

[2] Chen, L., Li, J., \& Zhao, W. (2005). Gender differences in self-repairs by Chinese non-English majors in their spoken English. Modern Foreign Languages (Xiandai Waiyu), 28(3), 279-287.

[3] Chen, L., \& Pu, J. (2007). A corpus-based analysis of self-repairs by college non-English majors. Foreign Language Education (Waiyu Jiaoxue), 28(2), 57-61.

[4] Gass, S. M., \& Varonis, E. (1985). Variation in native speaker speech modification to non-native speakers. Studies in Second Language Acquisition, 7(1), 37-58.

[5] Hutchby, I., \& Wooffitt, R. (1998). Conversation analysis: principles, practices and applications. Cambridge: Polity Press.

[6] Jefferson, G. (1974). Error correction as an interactional resource. Language in society, 3(2), 181-199.

[7] Jung, E. H. S. (1999). The Organization of Second Language Classroom Repair. Issues in Applied Linguistics, 10(2), 151-171.

[8] Kasper, G. (1985). Repair in foreign language teaching. Studies in Second Language Acquisition, 7(2), 200-215.

[9] Kazemi, A. (2006). A systemtatic study of self-repairs in second language classroom presentations: with some reference to social variables and language proficiency. Ph.D dissertation, The University of New South Wales.

[10] Kormos, J. (1998). A new psycholinguistic taxonomy of self-repairs in L2: A qualitative analysis with retrospection. Even Yearbook, ELTE SEAS Working Papers in Linguistics, 3, 43-68.

[11] Ochs, E. (2002). Becoming a speaker of culture. In C. Kramsch (ed), Language acquisition and language socialization: ecological perspectives. London: Continuum, 99-120.

[12] Pica, T., Kanagy, R., \& Falodun, J. (2009). Choosing and using communication tasks for second language instruction. In K. Van der Branden, M. Bygate, J. M. Norris (Eds.), Task-Based Language Teaching: A reader. Philidelphia, PA: John Benjamins B.V., 171-192.

[13] Sarangi, S. \& Roberts, C. (2002). Discoursal (mis)alignments in professional gatekeeping encounters. In C. Kramsch (ed), Language acquisition and language socialization: ecological perspectives. London: Continuum, 197-227.

[14] Schegloff, E. A., Jefferson, G., \& Sacks, H. (1977). The preference for self-correction in the organisation of repair in conversation. Language, 53(2), 361-382.

[15] Seedhouse, P. (1999). The Relationship Between Context and the Organization of Repair in the L2 Classroom. IRAL, 37(1), 59-80.

[16] Seedhouse, P. (2004). The interactional architecture of the language classroom: a conversation analysis perspective. Oxford: Blackwell Publishing.

[17] Shehadeh, A. (2001). Self-and Other-Initiated Modified Output During Task-Based Interaction. TESOL Quarterly, 35(3), 433-457.

[18] Van Hest, E. (1996). Self-repair in L1 and L2 production (Vol. 4). Tilburg: Tilburg University Press.

[19] Van Lier, L. (1988). The classroom and the language learner : ethnography and second-language classroom research. London: Longman.

[20] Wagner, J., \& Gardner, R. (2004). Introduction. In R. Gardner \& J. Wagner (eds.), Second language conversations. London: Continuum, 1-17.

[21] Wang, X. (2007). A Study of Age Differences in Speech Repair by English Learners. Journal of PLA University of Foreign Languages. (5), 65-71.

[22] Wong, J. (2000). Delayed next turn repair initiation in native/non-native speaker English conversation. Applied Linguistics, 21(2), 244-267.

Simin Zeng obtained her PhD in Second Language Education from the University of Cambridge. She currently serves as Assistant Professor at the School of Humanities and Social Sciences, Harbin Institute of Technology, Shenzhen, China. She is interested in researching issues in second language education, in particular, in a sociocultural approach. Her work mainly examines the evidence of L2 learners' self-regulation -their self-repairs, and seeks to explore pedagogical interventions that facilitate the growth of self-regulation from the perspective of dynamic assessment. 